\title{
Efficacy of Pimecrolimus in Fox-Fordyce Disease
}

\author{
Arani Chandrakumar ${ }^{1}$, Nick Francis ${ }^{2}$ and Nilesh Morar ${ }^{*}, 1$ \\ ${ }^{I}$ Department of Dermatology, Chelsea \& Westminster Hospital, London, UK; ${ }^{2}$ Department of Histopathology, Imperial \\ College Healthcare, NHS Trust, UK
}

\begin{abstract}
Fox-Fordyce disease (FFD) or 'apocrine miliaria' is a rare benign skin condition characterized by obstruction of the apocrine sweat gland. Treatment is generally unsatisfactory. A 15 -year-old girl presented with intensely pruritic lesions on her axillae, chest and groin. Histology from an axillary skin biopsy confirmed FFD. The patient was commenced on pimecrolimus cream twice daily for three months and then once daily for a further three months. After a month she had marked improvement of her symptoms. By three months, the papules had flattened. The lesions remained healed at follow up nine months after completing therapy. Pimecrolimus is a safe and easy to use option and we suggest that it may be considered as first-line therapy for FFD.
\end{abstract}

Keywords: Fox-Fordyce disease, apocrine miliaria, pimecrolimus, Elidel, treatment.

Fox-Fordyce disease (FFD), or 'apocrine miliaria' is a rare benign skin condition characterized by obstruction of the apocrine sweat gland [1]. Treatment is generally unsatisfactory. We report a patient with FFD successfully treated with pimecrolimus.

The pathogenesis of FFD is unclear but involves an initial keratin plug in the infundibulum of the hair follicle that then extends into the apocrine sweat duct. Intraepidermal parts of the apocrine duct rupture and microvesicles form. Acanthosis, spongiosis, dermal mucin and an inflammatory infiltrate result [2].

A 15-year-old girl presented with intensely pruritic lesions on her axillae, chest and groin. On examination, she had follicular papules and pigmentation confined to these sites (Fig. 1). She had been previously unsuccessfully treated with moderate potency topical steroids, antifungals, tretinoin and oral antibiotics prescribed by her GP. Histology from an axillary skin biopsy confirmed FFD. The patient was commenced on pimecrolimus cream twice daily for three months and then once daily for a further three months. After a month she had marked improvement of her symptoms. By three months, the papules had flattened, the pruritus had lessened and the postinflammatory hyperpigmentation was not as prominent (Fig. 2). The lesions remained healed at follow up nine months after completing therapy.

Fox-Fordyce disease runs a prolonged course. As well as the discomfort associated with pruritus, the lesions are cosmetically disfiguring. Case reports describe treatments with limited efficacy or associated with side effects that outweigh the benefits of treatment. Treatments include topical clindamycin, corticosteroids, tretinoin, benzoyl peroxide, oral isotretinoin, oral contraceptives, ultraviolet

*Address correspondence to this author at the Department of Dermatology, Chelsea and Westminster Hospital, 369 Fulham Road, London, SW10 9NH, UK; E-mail: nilesh.morar@chelwest.nhs.uk

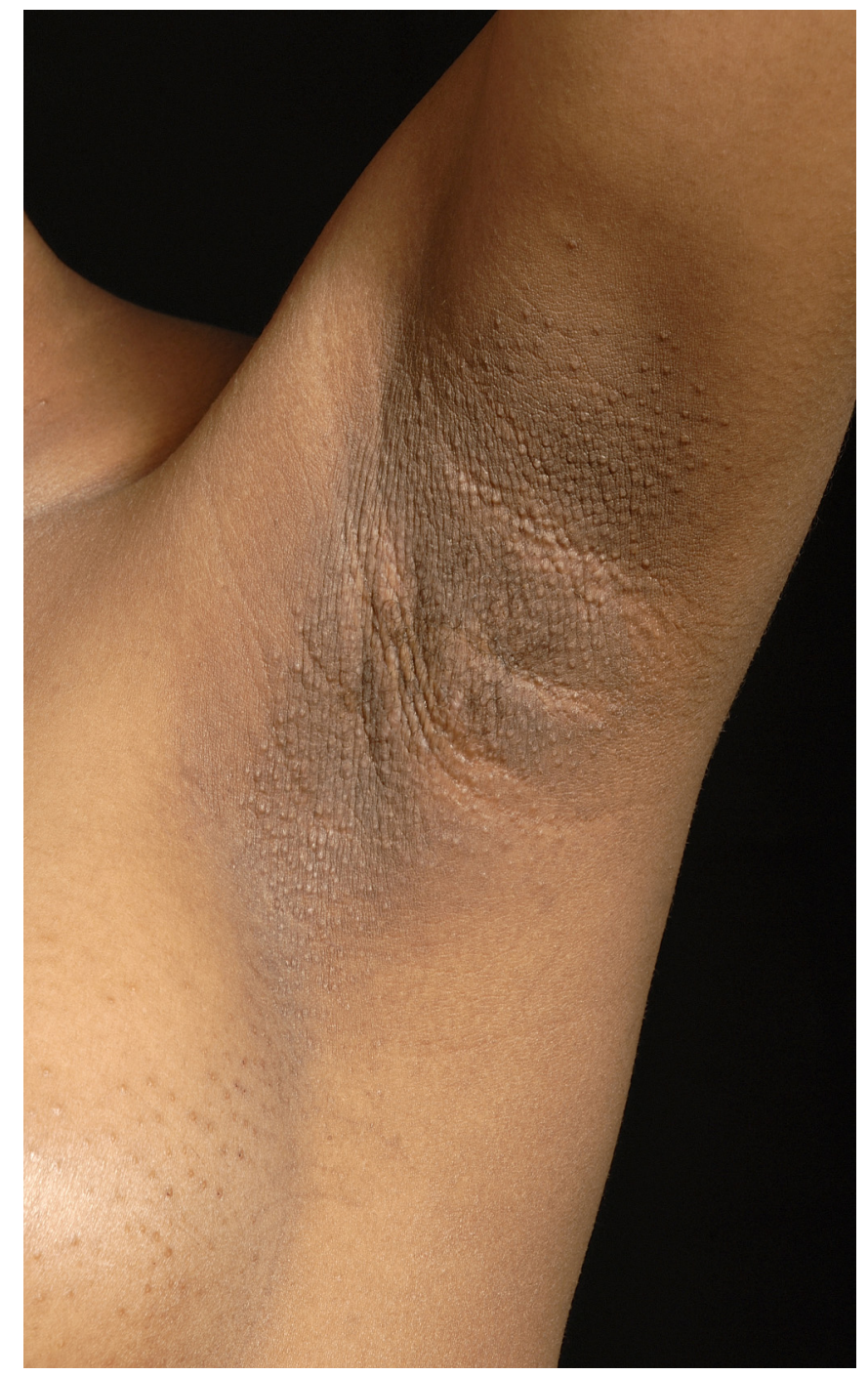

Fig. (1). Follicular papules and pigmentation seen in the left axilla of the patient pre-treatment. 


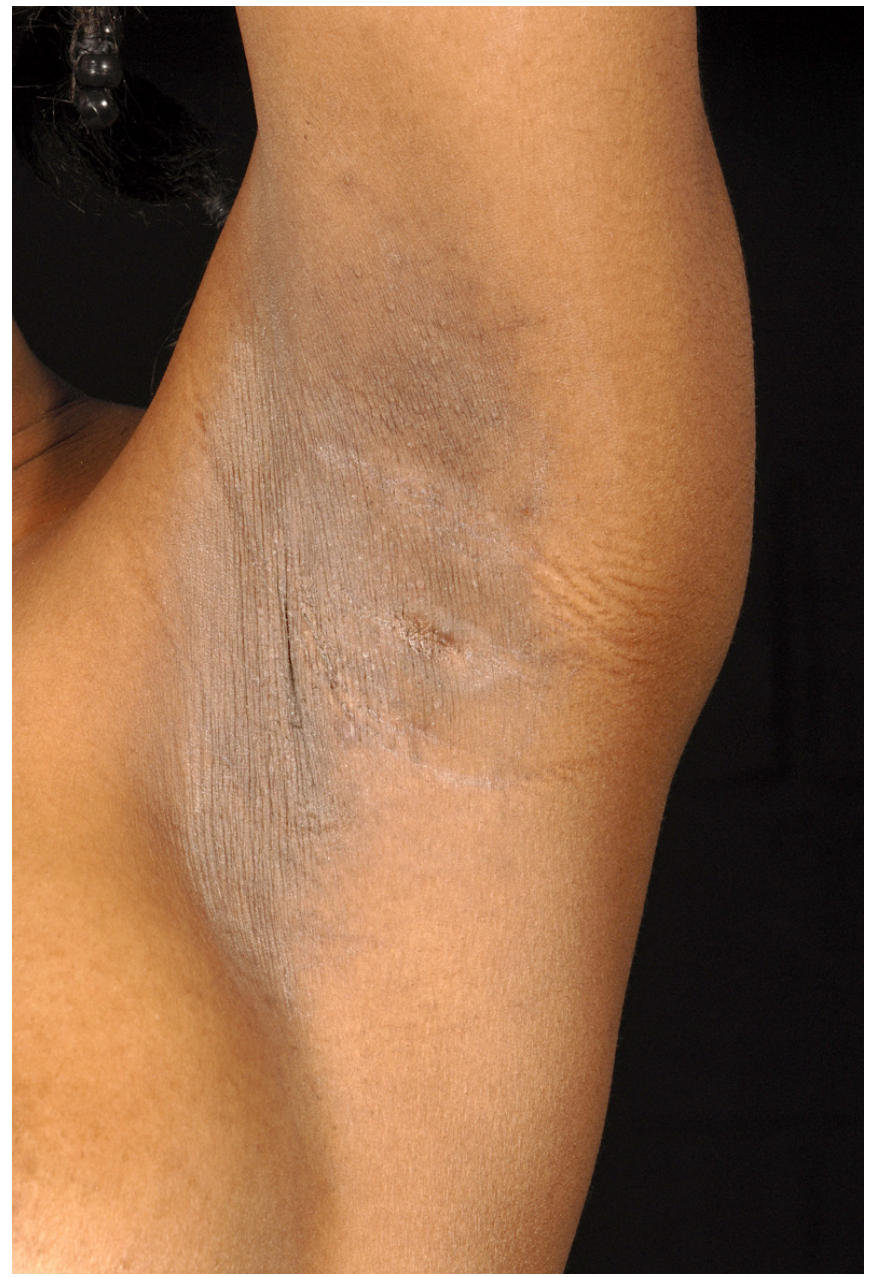

Fig. (2). The same patient 7 months after completing a 6 month course of pimecrolimus.

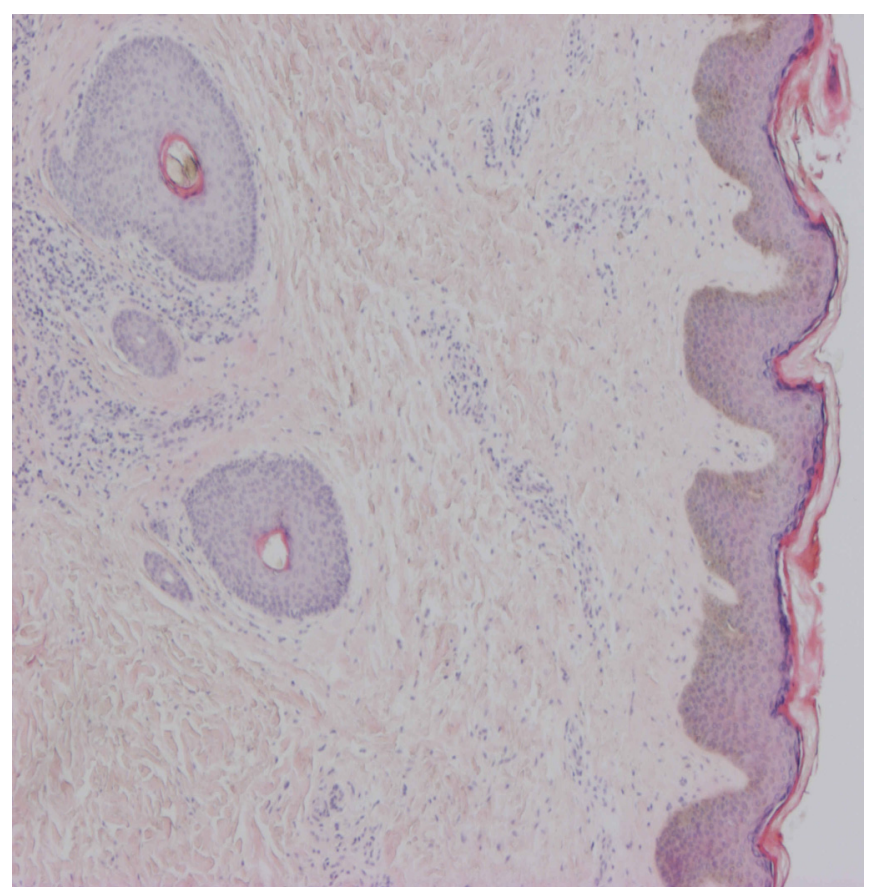

Fig. (3). Original magnification x 2. Fox-Fordyce disease. There is perivascular lymphocytes and eosinophils in the dermis with a perifollicular fibrosis and a focal chronic folliculitis. light, electrocoagulation, copper vapour laser, and liposuction-associated curettage. To date, there has been one previous case report demonstrating a successful response to eight weeks of pimecrolimus in three female patients after unsuccessful treatment with topical corticosteroids and tretinoin [3].

Pimecrolimus is currently licensed for use in mild to moderate atopic eczema. It is an ascomycin derivative. It binds to the cytosolic ligand receptor FK506 binding protein. This complex inhibits the enzyme calcineurin phosphatase, therefore preventing the dephosphorylation of the cytoplasmic component of the nuclear factor of activated $\mathrm{T}$ cells. The transcription of a number of inflammatory cytokines is therefore inhibited. These cytokines include IL2 , IFN- $\gamma$, IL-4 and IL-10. Other cytokines, such as IL-5 and TNF- $\alpha$, are decreased in production in a dose-dependent manner. Pimecrolimus also inhibits the transcription and synthesis of cytokines from mast cells and the release of the preformed mediators serotonin and $\beta$-hexosaminidase [4].

Pharmacokinetic studies of pimecrolimus have demonstrated negligible systemic absorption following topical application [3]. Side effects of topical corticosteroids are not seen with pimecrolimus.

Although tacrolimus is more efficacious than pimecrolimus for atopic eczema, both agents have a similar safety profile $[5,6]$. The cost of both products is also similar. Pimecrolimus (Elidel ${ }^{\mathbb{R}}$ ) is $£ 19.69$ for 30 grams. Tacrolimus $0.03 \%$ (Protopic $^{\circledR}$ ), on the other hand, costs $£ 19.44$ for 30 grams and $£ 21.60$ for the $0.1 \%$ preparation. There have been no case reports on the use of tacrolimus for FFD. Of note however, evidence for the potential long term complications of topical calcineurin inhibitors is controversial. Protopic ointment is greasy and as a result, compliance can be compromised especially when the preparation must be applied to the axillae twice daily. Our patient was unkeen for a greasy ointment and therefore pimecrolimus was thought to be a more suitable option.

Diagnosis of FFD often demonstrates features that are characteristic clinically but not histopathologically. The histology for our patient was not pathognomonic of the condition however it demonstrated features suggestive of FFD. Traditionally, the features seen histologically in this disease are infundibular plugging, acanthosis, parakeratosis, spongiosis, and a nonspecific infiltrate. 'Retention cysts' are thought to be diagnostic of FFD but are difficult to find. Bormate et al. (2008) advocate the identification of perifollicular 'foam cells', or pale foamy macrophages, as a hallmark of FFD [7]. In our patient, there was perifollicular fibrosis and a focal chronic folliculitis and although not diagnostic, it was felt these features were consistent with Fox Fordyce disease which complimented the clinical picture.

Pimecrolimus is a relatively safe and easy to use option and we suggest that is may be considered as first-line therapy for FFD. Pimecrolimus was developed specifically for the treatment of inflammatory skin diseases. Inflammation secondary to rupture of the apocrine duct in FFD may be reduced by pimecrolimus. There is no currently known mechanism to account for pimecrolimus preventing the keratin plugging and initial obstruction of the apocrine duct. However, pimecrolimus may play a role in this in view of a 
recent case of pityriasis rubra pilaris, another keratinisation disorder, completely clearing after use of pimecrolimus [8].

\section{REFERENCES}

[1] Champion RH. Disorders of sweat glands. In: Rook A, Ebling FJG, Wilkinson DS, Eds. Breathnach. Textbook of dermatology. $6^{\text {th }}$ ed. Oxford, England: Blackwell Scientific 1998; 2002.

[2] Sahn EE. A 35-year-old woman with a pruritic axillary rash. In: Sahn EE, Ed. Dermatology pearls. Adult and pediatric. Philadelphia: Hanley \& Belfus 1999; p. 223.

[3] Pock L, Svrcková M, Machácková R, Hercogová J. Pimecrolimus is effective in Fox-Fordyce disease. Int J Dermatol 2006; 45: 11345.

[4] Gupta AK, Chow M. Pimecrolimus: a review. J Eur Acad Dermatol Venereol 2003; 17: 493-503.
[5] Abramovits W, Fleischer AB Jr, Jaracz E, Breneman D. Adult patients with moderate atopic dermatitis: tacrolimus ointment $v s$ pimecrolimus cream. J Drugs Dermatol 2008; 7:1153-8.

[6] Fleischer $\mathrm{AB} \mathrm{Jr}$, Abramovits W, Breneman D, Jaracz E Tacrolimus ointment is more effective than pimecrolimus cream in adult patients with moderate to very severe atopic dermatitis. J Dermatol Treat 2007; 18: 151-7.

[7] Bormate $\mathrm{AB}$ Jr, Leboit PE, McCalmont TH. Perifollicular xanthomatosis as the hallmark of axillary Fox-Fordyce disease: an evaluation of histopathologic features of 7 cases. Arch Dermatol 2008; 144: 1020-4.

[8] Gregoriou S, Argyriou G, Christofidou E, Vranou A, Rigopoulos D. Treatment of pityriasis rubra pilaris with pimecrolimus cream 1\%. J Drugs Dermatol 2007; 6: 340-2.

Received: January 31,2010

Revised: April 14, 2010

Accepted: May 10, 2010

(C) Chandrakumar et al.; Licensee Bentham Open.

This is an open access article licensed under the terms of the Creative Commons Attribution Non-Commercial License (http://creativecommons.org/licenses/by-nc/ 3.0/) which permits unrestricted, non-commercial use, distribution and reproduction in any medium, provided the work is properly cited. 